\title{
As imagens e o silêncio sobre os indígenas a partir dos jornais Blumenauer Zeitung e Der Urwalsbote no contexto do Serviço de Proteção aos Índios (1916-1922)
}

Thiago Kistenmacher Vieira ${ }^{1}$

\section{Resumo}

Este trabalho tem como objetivo analisar a imagem dos povos indígenas a partir dos jornais blumenauenses Der Urwaldsbote e Blumenauer Zeitung no contexto de criação do Serviço de Proteção aos Índios (SPI), em seus primeiros anos de atuação: 1916 a 1922. Criado em 1918, o SPI foi uma instituição organizada pelo governo federal com o intuito de prestar auxílio aos povos indígenas e integrá-los à sociedade brasileira. Nosso método de pesquisa tratou de coletar notícias transcritas dos jornais supracitados e, posteriormente, discutir as imagens ali encontradas acerca dos povos nativos. A opção da imprensa como fonte se deu em virtude de ela poder ser considerada uma ferramenta pela qual as sociedades fabricam e transmitem suas escolhas morais, reflexões e representam concepções de sua época. Neste contexto, procuramos entender qual a imagem que aquelas mídias impressas ataram às populações nativas e como ela era discutida.

Palavras-Chave: Der Urwaldsbote. Blumenauer Zeitung. Serviço de Proteção aos Índios.

\begin{abstract}
This work aims to analyze the image of indigenous people from blumenauense newspapers Der Urwaldsbote and Blumenauer Zeitung in the context of the SPI that means Indians Protection Service, in its first years of operation: 1916 to 1922 . The SPI, created in 1918, was an institution organized by the federal government whose purpose was to assist the indigenous and integrate them into Brazilian society. Our research method sought to collect some transcribed news from the aforementioned newspapers and, after that, discuss the images found there concerning native peoples. The option of the press as source was given because it can be considered a tool by which societies produce and communicate their moral choices, reflections and represent conceptions of their time. In this context, we seek to understand which image those printed media tied to native peoples and how this was discussed.
\end{abstract}

Keywords: Der Urwaldsbote. Blumenauer Zeitung. Indians Protection Service.

1 Mestrando em Filosofia pela Universidade Federal de Santa Catarina (UFSC). E-mail: tkv1986@gmail. com 


\section{Introdução}

Nosso artigo pretende analisar os resultados obtidos em pesquisa voltada à questão da imagem dos indígenas na imprensa blumenauense dos anos de 1916 a 1922. Isso porque este foi um período importante no que tange às transformações de políticas nacionais, haja vista a mudança do Serviço de Proteção aos Índios e Localização dos Trabalhadores Nacionais (SPILTN) para o Serviço de Proteção aos Índios (SPI). Também porque somente após a criação desses serviços é que as populações indígenas e as questões que as envolviam passaram a ser noticiadas com maior regularidade.

Para tanto, iniciaremos nossa discussão abordando a conversão do SPILTN para o SPI e o que ela acarretou. Esses serviços baseavam-se na filosofia comtiana que marcou aqueles tempos. Assim, se é natural que esse pensamento tenha influenciado ações políticas empreendidas pelo governo federal, o que se observa é que ele se estendeu até os meios de comunicação local, a saber, aos jornais Blumenauer Zeitung ${ }^{2}$ e Der Urwaldsbote ${ }^{3}$, sendo o primeiro criado em 1879 por Hermann Baugartem, e o segundo pelo pastor Faulhaber em 1892 (FERNANDES, 2002: 15). Ambos eram, àquela época, escritos em alemão.

Para que compreendamos melhor os jornais com os quais lidaremos daqui em diante, vale frisar, com Seyferth (2007), que o Der Urwaldsbote foi aquele que "assumiu uma orientação mais nitidamente racista na construção da identidade teuto-brasileira, sob a influência do pangermanismo" (SEYFERTH, 2007: 110). Enquanto que o Blumenauer Zeitung possuía um discurso mais moderado quanto à questão indígena (DEUTCH-RITZ, 2015: 26). Além disso, a opção pelo Blumenauer Zeitung e pelo Der Urwaldsbote como fonte de pesquisa ocorre devido a ambos serem as mais influentes mídias daquele tempo no contexto blumenauense.

Antes de desenvolvermos o que os jornais diziam a respeito dos povos indígenas, discutiremos sobre o silêncio nessa imprensa no tocante ao tema, uma vez que, anos antes, era significativamente presente naqueles dois jornais. Por isso, a despeito de o Blumenauer Zeitung quase que se furtar a comentar a questão, decidiu-se por utilizá-lo ao lado do Der Urwaldsbote.

Depois de discutir o silêncio dos jornais, nos debruçaremos sobre as notícias encontradas durante a pesquisa, tendo como foco a forma como eram tratadas as populações nativas e, principalmente, as imagens sobre elas popularizadas por aqueles jornais blumenauenses.

\section{A mudança do SPILTN para o SPI}

Antes da criação do Serviço de Proteção aos Índios, foi criado, em 1910, o Serviço de Proteção aos Índios e Localização dos Trabalhadores Nacionais. O primeiro Serviço tinha por

2 Jornal de Blumenau.

3 O Mensageiro da Floresta. 
objetivo proteger os povos indígenas de ataques e também integrá-los à sociedade. Isso tudo sustentado nas ideias de progresso então acalentadas. Como vimos em Nötzold (2013: 148), essa proteção, como era entendida pelos agentes do Serviço de Proteção, não significava exatamente "defender direitos sobre territórios auto reconhecidos como tradicionais pelos indígenas e/ou a manutenção de sistemas socioculturais particulares e específicos de cada grupo étnico". Além do que, as leis federais permitiam, ao mesmo tempo, a proteção e o "apoio a práticas de violências" contra os povos nativos, que sugeriam o sucesso em ter "vencido", "civilizado" e/ou manipulado "inúmeros povos em proveito próprio, submetendo-os completamente, até fazê-los desaparecer sem deixar vestígios" (ALMEIDA, 2017: 19).

Sobre isso, conforme Souza Lima (1995), o SPILTN detinha um poder que visava tutelar os índios, organizá-los e acompanhá-los no que se entendia por evolução - evolução essa nos moldes comtianos que veremos adiante - e que acabavam por permitir aquela violência e proteção simultaneamente exercidas. $\mathrm{O}$ mesmo autor nos chama atenção para algumas diretrizes do Serviço. Vejamos alguns incisos do Artigo $2^{\circ}$ do Decreto $n .^{\circ} 9.214$, de 15 de novembro de 1911.

No $\S 3$ observamos o objetivo de colocar em prática meios a partir dos quais houvesse diminuição de invasão de terras dos povos indígenas por aqueles chamados “civilizados" e, também, que esses povos indígenas não invadissem o que era compreendido como terra dos "civilizados; no $\S 4$ a diretriz chama atenção para a necessidade de "respeitar a organização interna das diversas tribos, sua independência, seus hábitos e instituições, não intervindo para alterá-los senão com brandura e consultando sempre a vontade dos respectivos chefes;" no $\S 12$, por sua vez, se lê: "Promover, sempre que for possível, e pelos meios permitidos em direito, a restituição dos terrenos que lhes tenham sido usurpados (CARNEIRO DA CUNHA, 1992: 162).

Não obstante, o SPILTN objetivava também a construção de colônias agrícolas que usariam mão-de-obra indígena a partir das expedições oficiais realizadas pelos seus agentes ${ }^{4}$ e a expansão do controle do Estado sobre o território nacional (Ibid., 1992: 113). Em 1918, o LTN - Localização dos Trabalhadores Nacionais - transforma-se em um órgão particular ${ }^{5}$, dando origem ao SPI, que edifica postos para atrair e se aproximar dos povos indígenas, mas já sem a sigla LTN, transferida para o Serviço de Povoamento do Solo, ligado ao Ministério da Agricultura, Indústria e Comércio (BRINGMANN, 2015).

As ideias nas quais se sustentavam as atividades do SPILTN - e continuaram com o SPI - continham algo do liberalismo, do darwinismo, do spencerianismo e, especialmente, do positivismo comtiano (RODRIGUES, 2011: 204). Com essas ideias procedentes da Europa e, mediante ações nelas inspiradas, o que se ambicionava era a realização do progresso da sociedade brasileira. Aliás, segundo Hill (1996), as histórias dos povos nativos, nesse momento, aproximam-se das histórias dos europeus. Com suas ideias e ideais, inclusive, uma vez que o que se pensava na Europa seria aplicado em terras estrangeiras. Contudo, nascidas em um continente estranho

4 Esta iniciativa foi sancionada pelo Decreto $n^{\circ} .8 .072$, de 20 de junho de 1910.

$5 \quad$ Sancionada pelo Decreto-Lei n ${ }^{\circ}$. 3.454, de 6 de janeiro de 1918. 
ao território sobre o qual o SPILTN pretendia atuar, deve-se ter em mente a singularidade desse contexto e as dificuldades encontradas para sua implementação.

O fato é que o Serviço de Proteção, conforme assevera Lima (2015), foi construído como resultante de um acúmulo "simbólico e político" firmado pela Comissão de Linhas Telegráficas Estratégicas do Mato Grosso ao Amazonas. Esta Comissão, aliás, foi comandada por Cândido Mariano da Silva Rondon (1865 - 1958), naqueles tempos, tenente-coronel. Ele, segundo o mesmo autor, "se tornou o emblema das políticas de Estado pró-índio no Brasil" (LIMA, 2015: 429).

Como vimos, o SPILTN esteve imbuído do positivismo criado pelo filósofo francês Auguste Comte (1798 - 1857), que dividia o desenvolvimento da humanidade em três diferentes etapas. Logo, Comte criou aquilo que nomeou Lei dos Três Estados. A propósito, era mediante ela que os nativos eram classificados - daí a classificação que, mais adiante, observaremos nos jornais. Vejamos do que se trata.

O primeiro desses estados é chamado teológico, sendo ele dividido em três diferentes fases. Na primeira delas - fetichista - atribui-se vida e vontade própria aos objetos. A politeísta, segundo fase, era entendida como a época em que se confere aos deuses o controle sobre tudo. No monoteísmo, terceira fase do estado teológico, Deus é absoluto e controla todos os fenômenos. No estado metafísico, esses fenômenos são interpretados como resultantes de uma força abstrata que substituiriam as ações sobrenaturais. No último deles, o estado positivo, o ser humano renuncia às explicações anteriores e busca demonstrar os fenômenos única e exclusivamente por meio da ciência, ou seja, através daquilo que pudesse ser cientificamente comprovado (COMTE, 1825: 125-126). Os agentes do SPI, claro, consideravam-se no estágio último, no mais alto desse esquema. As populações indígenas, por seu turno, eram localizadas no primeiro.

Durante a formação inicial do Brasil República, as políticas que visavam o progresso, segundo seus adeptos, procuravam integrar as populações nativas na nova sociedade pelas quais se ansiava. Nesse ínterim, Teixeira Mendes ${ }^{6}$ chegou a declarar que "Nenhum homem de coração pode contestar que os selvagens são os senhores das terras que habitam, com títulos tão válidos como os que qualquer nação ocidental pode invocar, para justificar a posse do território que ocupa" (MENDES apud CARNEIRO DA CUNHA, 1987: 73). O Serviço de Proteção, comtiano em sua essência, iria exercer um poder relevante sobre os destinos dos povos indígenas.

Em 1916, o jornal Der Urwalsbote refere-se à presença do SPI na região, chamando atenção para uma casa sobre a qual "sobressai um mastro em forma de cruz na qual está hasteada a bandeira nacional e a de serviço" (DER URWALSBOTE, 1916, n64: 1). Interessante notar que, se os jesuítas iam até os sertões distribuindo objetos aos indígenas, vestindo-os e tocando músicas, os agentes do SPI, sob chefia de Rondon, quando se encontravam com os nativos, tocavam o Hino Nacional brasileiro (LIMA, 2015: 429).

Como os integrantes desse serviço viam a si mesmos como que no estado positivo, isto

$6 \quad$ Teixeira Mendes (1855 - 1927) foi um filósofo e matemático brasileiro, adepto das ideias positivistas. Assumiu a liderança da Igreja Positivista do Brasil em 1905. 
é, no mais "evoluído" dos três, não é por menos, então, que se julgavam no direito de tutelar aqueles que entendiam permanecer no estado inicial da inteligência ou da evolução humana. $\mathrm{E}$ não apenas isso.

O SPI entendia que os povos nativos não possuíam história. Afinal, não viam neles qualquer tradição que pudesse colocá-los como integrantes da sociedade brasileira. Se eles viviam à margem dessa sociedade, seria preciso mudar aquela situação. E, por meio da racionalização da cultura, mediante a qual se via diferentes fases no que se compreendia por evolução do espírito humano, esse serviço buscou impor seus ideais às comunidades nativas (HOERHANN, 2012: 61).

Mas, apesar de assim serem vistos, importa frisar o que escreveu Ribeiro (1986). Segundo ele, os defensores do positivismo acreditavam que, ainda que os indígenas permanecessem no primeiro estado - no caso, o fetichismo - não era de todo impensável que eles pudessem se desenvolver e progredir industrialmente (RIBEIRO, 1986: 134). Disso decorre o fato de que, para que os indígenas não fossem mal influenciados e permanecessem rumo ao aclamado progresso, era necessário inclusive que os agentes do Serviço de Proteção dessem exemplos. Segundo Hoerhann, os "desvios de conduta" dos ditos "civilizados", como, por exemplo, a "indisposição ao trabalho regrado, hábitos como tabagismo e a propensão ao alcoolismo" poderia prejudicar todo o projeto de "civilizar" e/ou "pacificar" os indígenas (HOERHANN, 2012: 69).

O que se vê, dentre outras coisas, é que, embora a sigla do Serviço de Proteção tenha mudado de SPILTN para SPI, a questão do trabalho vai permanecer como um elemento essencial no processo de "civilização" capitaneado pelos positivistas. Contudo, esse serviço sofria com os investimentos deficitários por parte do governo federal. Como assevera Bringmann (2015), havia inúmeras dificuldades apresentadas pelo SPI para deslocar agentes até as regiões que necessitavam de maior efetivo. Isso ocorria especialmente devido à falta de recursos financeiros. E os jornais por nós analisados também trataram da questão.

Para além do empreendimento de tentar pacificar os indígenas, o Serviço, mais do que isso, deveria, segundo o Der Urwaldsbote, "proteger os colonos". Em função disso o jornal reivindica maiores cuidados para com o projeto federal. Do contrário, caso o Serviço "não mostrar resultado, logo sirva para proteger os colonos, era dinheiro e trabalho jogado fora" (DER URWALDSBOTE, 1916, n' 31: 3).

O mesmo jornal, sobre o problema de investimento, afirma: "agora já um ano e meio, não enviam mais dinheiro [...] e muitas vezes não é capaz de obter carne e outros alimentos para os trabalhadores no Plate ${ }^{7}$ e ainda os índios talvez presentes" (Ibid., 1916, n64: 1). Mais tarde, ele volta a tratar da carência de recursos para o SPI e diz que

Os deputados, quando elaboraram o orçamento anual, deveriam ter diante dos olhos e só dizer, que pessoas que se dispõem a este serviço, sejam eles operários ou dirigentes deveriam receber pontualmente seu dinheiro, pois os primeiros fazem pelo menos três vezes por mês, alguns até

$7 \quad$ Rio localizado na região do alto Vale do Itajaí. 
semanalmente, enquanto os diretores pelo menos duas vezes por mês. Além disto, ainda soma-se o que deve ser protegido neste serviço e que é muito precioso não só para o Brasil ou para a America [sic] do Sul, mas sim para toda a humanidade (Ibid., 1916, N85-86: 1).

A julgar pela última afirmação do trecho acima, vimos como o colaborador do Der Urwaldsbote considerava fundamental a manutenção do Serviço de Proteção. Para ele, não só o Brasil ou a América do Sul ganhariam com isso, mas "toda a humanidade." Entretanto, se ele deixava tão claro que essa era uma questão tão importante "para toda a humanidade", por que, desde 1916, há quase que um desaparecimento total do tema indígena naquela imprensa? É este silêncio que discutiremos a seguir.

\section{O silêncio da imprensa relativamente à questão indígena}

Durante a pesquisa, verificou-se que, quando comparado aos anos anteriores - até 1915, quando as discussões em torno da "questão indígena" foram abundantemente debatidas -, que o jornal Der Urwalsbote se ocupou especialmente de outros assuntos. Entre eles estão a imigração alemã, falecimentos e a Guerra do Contestado (1912 - 1916). Isso tudo além da Primeira Guerra Mundial (1914 - 1918), que, como se vê, foi o tema predominante durante esses anos de conflito.

Por isso, com o propósito de demonstrar como o jornal se apartou do tema de forma considerável, salientamos que o Der Urwaldsbote abordou a questão algumas vezes em 1916, nada falou em 1917 e só retornou às discussões referentes aos povos indígenas em 1924. Isto é, apenas dois anos depois da data máxima contemplada originalmente em nosso projeto de pesquisa -1922 . Esta, acreditamos, é uma informação significativa. Pois, conforme Rodrigues (2017), nos anos anteriores, principalmente entre 1909 a 1915, as notícias relacionadas às populações indígenas abundavam.

Sobre essa disparidade, a título de uma demonstração detalhada, observemos a quantidade de notícias respeitantes à questão indígena publicadas pelo Der Urwaldsbote. Primeiramente entre os anos de 1909 a 1915. Em 1909: 13 notícias; 1910: 4 notícias; 1911: 21 notícias; 1912: 8 notícias; 1913: 8 notícias; 1914: 1 notícia; 1915: 3 notícias. Agora vejamos o número de textos que abordaram a questão indígena entre os anos de 1916 a 1922. Em 1916: 4 notícias; e em 1914, o mesmo jornal publica apenas 1 notícia sobre este tema. O Blumenauer Zeitung, por sua vez, publica: 1910: 1 notícia; 1911: 4 notícias; 1915: 1 notícia.

A respeito do silêncio do jornal Blumenauer Zeitung, algumas hipóteses foram levantadas. Uma delas é de que a interrupção brusca de textos tratando da questão indígena tivesse sido em virtude do falecimento do Dr. Hugo Gensch, escritor ativo daquele jornal. Tal hipótese, contudo, acabou sendo descartada. Pois logo vimos que Gensch faleceu apenas em 1922. Isto é, se desde 1916 seu jornal não mais abordou questões relativas aos povos indígenas, tudo indica que não foi esta a razão pela qual o Blumenauer Zeitung descontinuou suas argumentações em torno daquele 
assunto.

Ainda sobre o silêncio, pergunta-se: o que ele pode significar, visto que o calar-se sobre um tema não o torna inexistente? Segundo Orlandi (2001), muitos entendimentos são erigidos sobre esse silêncio: pode ser um sinal de que "há em toda situação de fala relações que jogam com o não-dito, uma política do dizer determinada para fixar sentidos onde há múltiplos sentidos possíveis" (ORLANDI, 2001: 135).

Por causa do constatado silêncio, nossa pesquisa, cujo recorte histórico estava entre 1916 e 1922, avançou seis anos mais, ou seja, até os originais em alemão do ano de 1928. No entanto, a mesma coisa foi notada. Destarte, considerando o silêncio que se estabeleceu na imprensa daqueles anos, é razoável afirmar que essa omissão contribuiu para que a imagem anterior dos povos indígenas como selvagens, silvícolas e perigosos, entre outras coisas, se apresentasse quase como definitiva. Graças às concepções positivistas, ao silêncio da imprensa sobre a questão indígena e às poucas notícias que se ocupam em apontá-lo como "selvagem", impõem-se sobre os nativos uma interpretação problemática.

Tentando elaborar possibilidades de interpretação para o que encontramos, várias foram as hipóteses levantadas através do embasamento documental e bibliográfico. A questão indígena e os trabalhos empreendidos pelo SPILTN são discutidos em ambos os jornais pesquisados até 1915, no entanto, depois de 1916 - lembrando que o SPILTN passa para SPI apenas em 1918 - existe a sobredita queda no que se refere ao tema. Não foram encontradas evidências que pudessem nortear-nos sobre as razões dessa mudança.

Contudo, a despeito de todo esse mutismo, o pouco que se falou foi suficiente para que compreendêssemos a imagem que se projetou sobre os povos nativos. Esta, que é a espinha dorsal desse artigo, será analisada no tópico subsequente.

\section{A imagem do indígena segundo os jornais Der Urwaldsbote e Blumenauer Zeitung}

Sobre a questão da imagem dos indígenas veiculada pelos jornais selecionados, observaremos algumas notícias coletadas durante a pesquisa. Antes, porém, faz-se necessário considerar duas questões. Primeiramente, é importante esclarecer o que aqui entendemos por imagem. Em segundo lugar, é preciso demonstrar o porquê de a nossa pesquisa ter optado pelos jornais como fontes para o trabalho.

A imagem, segundo Caleffi (1997), deve ser entendida por um imaginário criado com fundamentação em um objeto para que tal projeção possa ser defendida. Sendo a imagem diferente do objeto, é desse modo que são construídas as representações. Além do mais, entende-se por imagem um conteúdo específico do imaginário projetado com base em um objeto. Isso significa que, para que se possa empreender a projeção de um imaginário, deve-se existir algo, um objeto, que sirva como um "gancho". Sobre ele é que "o conteúdo do imaginário se projetará, formando 
a imagem (Imago $)^{8}$, que é distinta do objeto, abrindo uma das vias das construções das representações" (CALEFFI, 1997: 50). Essas representações - ou símbolos -, segundo Lataiff (1996), são apenas imagens de ideias, sejam elas conscientes ou inconscientes, que os sujeitos extraem de suas relações e/ou de si mesmos (LATAIFF, 1996: 16).

Os jornais podem, por sua vez, ser concebidos como instrumentos pelos quais a sociedade produz modelos. E, dado que a imprensa é um objeto significativo no que concerne às opiniões da sociedade no geral, é salutar tê-la em alta conta quando se busca compreender as imagens dos povos indígenas popularizada naqueles tempos.

Durante o início do século XX, a imprensa da região do Vale do Itajaí apresentou um importante desenvolvimento, o que proporcionou maior alcance de suas publicações - ou, no presente caso, das imagens fabricadas - e influência nas opiniões que veiculavam (ALVES, 2000: 74). A análise da imagem dos povos indígenas naquela mídia impressa, à vista disso, procurou verificar como estes eram retratados no contexto da criação do SPI, uma vez que só então ele passou a ser o sujeito da notícia.

Tendo isso claro, avancemos para os artigos encontrados por ocasião da nossa ida às fontes. No jornal Der Urwaldsbote, em texto assinado por Haeck', lê-se: "Se eu comparo o comportamento dos índios com o da minha primeira visita, então sem dúvida foi dado um grande passo no progresso em sua educação" (DER URWALDSBOTE, 1916, n64: 1). Aqui se nota que o Serviço de Proteção - ainda SPILTN - encarnava não apenas uma instituição voltada à proteção dos nativos, mas, fazendo jus ao seu nome, atuava como um órgão por meio do qual esses povos poderiam "evoluir" na escala do desenvolvimento humano advogada pelos positivistas - lembremos da Lei dos Três Estados elaborada por Comte. Afinal, os povos indígenas eram tidos como seres não evoluídos - eis uma primeira imagem percebida.

A segunda imagem depreendida dessas notícias concerne àquela que identificava os povos indígenas como "selvagens". Há anos que esta classificação circulava nos textos da imprensa blumenauense (RODRIGUES, 2017). Este "selvagem", portanto, implicava na significação de que ele fosse perigoso, violento, e estivesse disposto a atacar os colonos. Isso por serem classificados como que estando na idade "primitiva" do ser humano. De fato, era essa concepção que se tinha dos povos nativos, pois, no dia 21 de abril de 1916, o Der Urwaldsbote, referindo-se aos botocudos ${ }^{10}$, afirma que eles vivem: "por assim dizer na idade primitiva do homem e para a ciência é uma

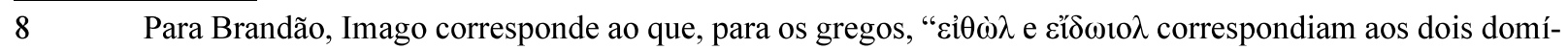
nios imagéticos da representação - a) um, o do mundo que temos diante de nós, por meio de desenhos, gravuras, esculturas, pinturas, fotografias; b) outro, o de nosso mundo imaterial, formado em nossa mente, como nossas fantasias, visões, sonhos, pensamentos -; os romanos empregavam um conceito que abarcaria ambos os domínios: imago.” Cf. BRANDÃO, Jack. Eikón, Eidolon, Imago. Imagem: étimo e emprego dissuasório. Revista Lumen et Virtus. Vol. VII. no 16. Agosto/2016. Disponível em: http://www.jackbran.com.br/lumen_et_virtus/numero_16/PDF/ EIK\%C3\%93N-EIDOLON\%20E\%20IMAGO_IMAGEM\%20COMO\%20PODER\%20DISSUAS\%C3\%93RIO.pdf. Acesso: 30/07/2019.

9 Não encontramos referências que pudessem esclarecer quem é o sujeito que assina este texto.

10 Sobre a histórias dos botocudos, ver: PARAÍSO, Maria Hilda B. Os Botocudos e sua Trajetória Histórica. In: CARNEIRO DA CUNHA, Manuela (Org.). História dos Índios no Brasil. - São Paulo : Companhia das Letras : 
fonte inesgotável de conhecimentos, cujos tesouros precisam ser rapidamente e profundamente levantados" (DER URWALSBOTE, 1916, nº 85-86: 1, grifo nosso).

Sobre tal discurso, eis alguns textos jornalísticos nos quais tal designação é detectada: "Como estes selvagens já se habituaram ao sal e a farinha [sic] e a comida [sic] de que nós comemos, não seria tão difícil fixá-los em definitivo (Ibid., 1916, n64: 1, grifo nosso). E outra: "A matança de gado pelos selvagens também acabou (Ibid., 1916, n64: 1, grifo nosso); e, referindo-se aos botocudos, o autor escreve: "Na estação durante minha permanência estavam presentes cerca de setenta selvagens, homens, mulheres e crianças (Ibid., 1916, nº5-86: 1, grifo nosso).

Há, dessa maneira, a necessidade de uma observação atenta sobre tais constatações, pois como diz Orlandi (1999), elas são feitas de modo que "o discurso apareça como instrumento (límpido) do pensamento e um reflexo (justo) da realidade" (ORLANDI, 1999: 51). Todavia, sabemos que, mais do que "límpido" e "justo", o discurso propagado pelos agentes do SPI e pelos que assinavam os textos dos jornais, tinha como influência um sistema filosófico importado de outro continente. Desse modo, é bastante claro o porquê de aquelas ações causarem estranheza ao tentar adaptar os indígenas aos seus moldes.

No intuito de retratar o modo como os agentes positivistas e alguns colaboradores dos jornais viam os indígenas, importa destacar um trecho no qual lemos o seguinte:

\footnotetext{
Como agora a tribo indígena, residente nas cercanias da Hansa ${ }^{11}$, mais cedo ou mais tarde, está destinada a desaparecer, seria lamentável se nosso município deixasse escapar a oportunidade, em instalar um museu, onde serão expostos os objetos, utensílios e fotografias, etc., como prova para as gerações seguintes dos perigos que enfrentaram os primeiros colonos neste país e da existência verdadeira dos índios, nas quais até hoje muita gente não acredita (DER URWALDSBOTE, 1916, nº4: 1).
}

A criação deste museu, como informa Haeck, o autor do texto, chegou a receber a "compreensão de diversas personalidades e também os dois diretores do serviço de proteção aos índios, senhor Dr. Stroube e senhor Eduardo Hoerhann, que declararam-se a favor de um museu" (Ibid., 1916, n 64: 1) para esses fins. Este museu, segundo a mesma publicação, deveria ficar sob a responsabilidade da Câmara Municipal de Blumenau que, segundo o autor, deveria "apoiá-lo com todos os meios" (Ibid., 1916, n64: 1) que dispusessem. Vê-se que os povos indígenas continuavam sendo concebidos como seres exóticos, que deveriam se submeter a um processo de “evolução e educação", o qual, evidentemente, deveria ser dirigido por aqueles mesmos agentes encarregados do SPI. A concepção de museu naquele período era de fazer com que a posteridade reinterpretasse o passado e visse o "perigo" sob o qual os colonos haviam estado - aqui os povos indígenas aparecem mais uma vez como perigosos. 
Essa investida serve, também, para marcar as fronteiras do binarismo nós-eles. Isso congela essa diferença "no tempo e na história, confere poder a autoridade estabelecida sobre os outros, [...] e leva ao policiamento da diferença" (HALL, 2003: 89). Então, além das práticas políticas colocadas em curso ao longo das expedições, dos encontros com os variados povos nativos, o museu, aqui, demonstra como sua criação tinha como objetivo fixar a diferença e, acrescido a isso, justificar aquele "policiamento da diferença", como salientado por Hall. Isso pode, aliás, ser observado durante a leitura dos textos veiculados pelos jornais a respeito da situação envolvendo os povos indígenas. Quer dizer, o "policiamento da diferença” surge quando os jornais abordam a referida temática.

Sobre tal iniciativa, é valoroso termos em mente que ações como essa auxiliariam também na construção de memórias coletivas e, nessa esteira, na formação de uma identidade nacional. A respeito dessa tentativa de construir uma identidade nacional, importa salientar o mecanismo dessa construção, sua função. De acordo com Woodward (2000: 9), uma identidade precisa, para que exista, necessariamente de algo que se considere "fora dela". Ou seja, aqui, quando se compreende os povos indígenas como distantes dos povos que viam a si mesmos como civilizados - os europeus colonizadores e idealizadores do museu -, ao mesmo tempo são os povos nativos que fornecem as condições para que eles - os europeus - possam identificar-se como almejavam. Isto é, os povos nativos, então, são não-europeus. E assim, através desse mecanismo é que a identidade nacional objetivada pelos colonizadores buscava ser criada.

A propósito, com essa representação que separa a identidade - dos colonizadores - com a diferença - os povos nativos -, pode-se sustentar um sistema de poder. Isso porque, aqueles que detém o poder de criar essa representação "tem o poder de definir e determinar identidade. É por isso que a representação ocupa um lugar tão central na teorização contemporânea sobre a identidade e nos movimentos sociais ligados à identidade" (HALL, 2000: 91).

Projetos assim, de poder, até, segundo Leal (2014: 14), eram executados principalmente por meio da construção de museus ou monumentos, em especial a partir da segunda metade do século XIX - e que, como vimos, continuam exercendo um papel importante também no início do século XX. Desse modo, a ideia era fazer com que não houvesse espaço para que a posteridade duvidasse da existência daqueles povos "violentos", daquele "perigo vermelho", termos continuamente reiterados. Em outras palavras, a construção de um museu no qual se pudesse expor aqueles povos, serviria para justificar a narrativa de repressão a qualquer atitude tomada pelos nativos não conformados com o avanço do Serviço de Proteção e seus agentes.

Se Brefe assinala que o museu pode se transformar num lugar através do qual se possa entender o que pretendiam seus idealizadores e como, por meio dele, fazem representar seus objetos, os jornais pesquisados nos abastecem com declarações que falam quase como por si só. Afinal, o próprio texto jornalístico antes destacado informa a necessidade da criação de um museu para que as próximas gerações entendessem o perigo pelos quais haviam passado seus ascendentes. Assim, lendo tal objetivo através do que nos indica Woodward, quando fala a respeito das 
mulheres, (2000: 10-11), a criação dessa identidade seria fortemente marcada pela diferença entre os grupos étnicos - colonizadores e povos nativos, no presente caso - que se poderia apresentar no museu - também em "lugares particulares e em momentos particulares". Ademais, a diferença é fomentada por meio de sistemas de classificação que criam sistemas que servem à exclusão e, como assinala, as identidades são construídas de modo que ajudem na compreensão do que é o "eu" (SILVA, 2000), o que, nessa questão de diferenciação entre povos nativos e colonizadores, atua claramente em detrimento dos primeiros.

Mas, se em 1916 o Der Urwaldsbote clama pela construção de um museu que registre os perigos pelos quais passaram os colonos, em 1924, o discurso permanece o mesmo. Constatamos isso quando o autor do jornal, abordando a falta de pagamento aos agentes do Serviço de Proteção, assevera que, caso não fossem devidamente remunerados: "Então o perigo vermelho poderia ficar pior do que já foi há anos passados" (DER URWALDSBOTE, 1924, nº16: sem paginação). O que se vê, então, é a ideia de que os povos indígenas eram perigosos e exóticos - daí que sua existência deveria ser comprovada mediante a criação de um museu que, como vimos, colaboraria para legitimar a violência empreendida contra os povos nativos. Lembremos, inclusive, que, se tal museu, como vimos acima, acabasse por expor fotografias, ferramentas, utensílios e quaisquer outros objetos, é bastante razoável imaginar que, caso o museu saísse do papel e fosse de fato construído, haveria também exposição de armas indígenas. Desse modo, o discurso tão propagado acerca do "perigo vermelho" teria ainda mais sustentação - ao menos no imaginário das gerações vindouras. E, como escreve Almeida (2017: 20), essa concepção seria apresentada "em nossa historiografia", além de ser sustentada pela "mídia e pelas narrativas históricas em escolas, colégios e universidades, essas ideias foram facilmente incorporadas no imaginário da população brasileira, com imensos prejuízos para todos, mas principalmente para os índios".

Visto isso, e sendo os povos indígenas tidos como "perigosos" e "violentos", que deveriam ser temidos, o que seria preciso fazer? A resposta, segundo aquela concepção: "pacificá-los". Esta é uma afirmativa encontrada em texto publicado pelo jornal Der Urwaldsbote, e que diz: "Se o governo federal pretende pacificar os índios..." (Ibid., 1916, n³1: 3). Eis mais uma das imagens constatadas: se aos povos indígenas atribuía-se o rótulo de perigoso, seria preciso que fossem "pacificados", como se tais povos precisassem ser "domesticados" para serem incluídos ao programa nacional.

Outro retrato dos povos nativos propagado pelo Der Urwaldsbote aparece quando esse jornal, na época já apontando para os problemas de investimento nas obras do SPI, fala sobre os "costumes" dos indígenas. Sua afirmação é a seguinte:

Mas como agora o governo federal não lhes envia dinheiro [ao SPI] e o crédito já foi gasto ao extremo, não podem adquirir alimentos e os índios são obrigados a recair em seus velhos costumes, que é roubar para não morrer de fome (DER URWALDSBOTE, 1916, n³1: 3). 
Quer dizer, o índio, além de todas as imagens sobre ele fabricadas, é concebido aqui como um sujeito que tem no roubo um costume.

Considerando as colocações acima, salta aos olhos o fato de que os jornais, quando escreviam sobre os povos indígenas, tendiam à homogeneização. Entretanto, as diferenças existem no tempo e no espaço. Isso a despeito das tentativas de compreender os povos nativos como se tivessem as mesmas características, formação cultural, etc. (HALL, 2003). Rodrigues (2005) também salienta que, durante o processo de colonização, seja da América portuguesa ou espanhola, houve uma construção de identidade para os povos indígenas. Eis um acesso direto para a rota das generalizações. Não ocorria aos autores dos textos que, bem como os povos europeus, os indígenas também eram diversos, possuíam modos de viver, culturas e comportamento diversos. Esta, então, é outra imagem criada: a de que os indígenas eram todos iguais, a mesma coisa, um povo único. Com efeito, ignorada a diversidade dos povos indígenas, todos eram concebidos como selvagens perigosos que precisavam ser pacificados e evoluir para que deixassem de roubar e atacar os colonos.

\section{Conclusão}

Após as discussões realizadas e o que se pode apreender das fontes, considerando o contexto no qual eram produzidas, nota-se um silêncio perturbador no que tange às questões indígenas. Isso principalmente por parte do jornal Blumenauer Zeitung. Aliás, essa diferença com relação à quantidade de textos relacionados aos povos indígenas torna-se mais surpreendente ainda quando a comparamos ao número de artigos sobre o tema que foi veiculado entre os anos de 1909 e 1915 - período em que houve muito mais atenção em torno da "questão indígena", como se costumava dizer.

Tal silêncio, portanto, abre outras possibilidades de pesquisa. Com esse dado, é possível, por exemplo, valorizar o referido silêncio a fim de perguntar quais suas razões, principalmente porque a questão indígena era nevrálgica na região do Vale do Itajaí e, até 1915, frequentemente noticiada. Por isso a pergunta: qual a razão desse silêncio? Afinal, as discussões em torno dos povos nativos estavam longe de serem resolvidas.

Olhando para o problema sob a ótica de Orlandi (1995), podemos cogitar a possibilidade de que isso signifique a tentativa de invisibilizar os povos indígenas. Pois um silêncio tão notável numa imprensa tão importante e, além do mais, sobre questões envolvendo os povos indígenas até 1915 tão reiteradamente abordadas -, não nos parece ser inocente. Conquanto, a fim de não tirarmos conclusões sem nos debruçarmos sobre o tema, no momento, não é possível afirmarmos com a mínima segurança quais foram as causas pelas quais houve silêncio relativamente às questões indígenas.

No que corresponde à imagem dos indígenas na imprensa blumenauense daqueles anos, é razoável afirmar que não há imagem, mas imagens. Isso porque os povos indígenas eram visto 
como pessoas que deveriam evoluir - para isso a atuação do SPI. Em segundo lugar, aos povos nativos era atribuída a ideia de que eram selvagens. Ademais, os textos os classificam como exóticos e primitivos. Por causa disso, seria preciso, conforme defendeu o Der Urwaldsbote em 1916, criar um museu no qual seriam expostos objetos e fotografias indígenas. Essa seria uma forma de a posteridade observar quão "perigosos" eram esses povos. Consequentemente, eles deveriam ser pacificados - daí novamente a necessidade do SPI. Além de tudo isso, a imprensa apresentava os povos indígenas como aqueles que têm por costume roubar, implicando sobre eles os valores que atribuímos à imagem do ladrão. Assim, conforme aponta Almeida (2017: 34), se levarmos em consideração quantas gerações posteriores acabaram por ser educadas a partir de perspectivas tais como essas, pode-se ter uma ideia do prejuízo causado.

Por fim, concluímos com uma última imagem possível de ser observada: a de que os povos indígenas eram "uma coisa só". Isso em razão de que jornais não faziam diferença entre eles. A mídia daquele momento, como vimos durante nosso trabalho, desconsiderava toda distinção que pudesse haver entre as diferentes comunidades indígenas. Como resultado, todos os povos nativos da região eram compreendidos por uma só imagem - esta, manifestamente composta por todas aquelas outras imagens negativas apresentadas anteriormente.

\section{Referências Bibliográficas}

ALMEIDA, Maria Regina Celestino. A atuação dos indígenas na História do Brasil: revisões historiográficas. Revista Brasileira de História. São Paulo, v. 37, nº 75, 2017.Disponível em: http://www.scielo.br/pdf/rbh/v37n75/1806-9347-rbh-2017v37n75-02.pdf. Acesso em: 20/09/2019.

BREFE, Ana Cláudia Fonseca. Os primórdios do museu: da elaboração conceitual à instituição pública. Proj. História, São Paulo, 17. Nov. 1998.

BRINGMANN, Sandor Fernando. Entre os Índios do Sul: Uma análise da atuação indigenista do SPI e de suas propostas de desenvolvimento educacional e agropecuário nos Postos Indígenas Nonoai/RS e Xapecó/SC (1941-1967). Tese (Doutorado em História). Universidade Federal de Santa Catarina. Florianópolis, 2015.

CALEFFI, Paula. A identidade atribuída: um estudo da historiografia sobre o índio. Estudos Leopoldenses, Série História, São Leopoldo: Unisinos, v. 1, n. 1, p. 50-64, 1997.

CARNEIRO DA CUNHA, Manuela (Org.). Legislação indigenista no século XIX. São Paulo: Editora da USP: Comissão Pró-Índio de São Paulo, 1992.

COMTE, Auguste. Cours de philosophie positive: première leçon. In: La science sociale. France: Gallimard, 1972.

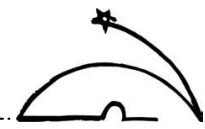


DEUTCH-RITZ, Ute. Germans and Indians in Brazil: The Transatlantic Construction of Ethnic Identity In the Discourse of Indian Protection. In: FINGER, A; KATHÖFER, Gabi; LARKOSH, Christopher. KulturConfusão - On German-Brazilian Interculturalities. Univ. of Denver, USA; C. Larkosh, Univ. of Massachusetts Dartmouth, USA, 2015.

FERNANDES, M. L. Primeiros passos da imprensa catarinense. In: $3^{\circ}$ Encontro Nacional da Rede Alfredo de Carvalho, 2005, Novo Hamburgo. Preservando a memória da imprensa e da mídia no Brasil. Novo Hamburgo: Feevale, 2005. v. 01.

GEERTZ, Clifford. A interpretação das culturas. Rio de Janeiro: Guanabara Koogan, 1990.

HALL, Stuart. Da Diáspora: identidades e mediações culturais. Belo Horizonte : Editora UFMG; Brasília : Representação da UNESCO no Brasil, 2003.

HILL, Jonathan (Org.) History, Power and Identity: ethnogenesis in the Americas, 1942- 1992. Iowa City: University of Iowa Press, 1996.

HOERHANN, Rafael Casanova de Lima e Silva. O Serviço de Proteção aos Índios e os Botocudo: A Política Indigenista através dos relatórios (1912-1926). Florianópolis: UFSC, 2005. 125 p. Dissertação (Mestrado). Programa de Pós Graduação em História, Centro de Filosofia e Ciências Humanas, Universidade Federal de Santa Catarina, Florianópolis.

O Serviço de Proteção aos Índios e a desintegração cultural dos Xokleng(1927 - 1954). Tese (Doutorado em História). Universidade Federal de Santa Catarina, Florianópolis, 2012.

LEAL, Elisabete. PAIVA, Odair da Cruz. (Org). Patrimônio e história. Londrina: Unifil, 2014.

LIMA, Antonio Carlos de Souza. Um Grande Cerco de Paz. Poder Tutelar, Indianidade e Formação do Estado no Brasil. Petrópolis: Vozes, 1995.

Sobre Tutela e Participação: povos indígenas e formas de governo no Brasil, Séculos XX/XXI. Mana, vol.21, no.2, Rio de Janeiro. Aug. 2015.

LITAIFF, Aldo. As divinas palavras: identidade étnica dos Guarani-Mbya. Florianópolis: Ed. da UFSC, 1996.

ORLANDI, Eni P. As formas do silêncio: no movimento dos sentidos. 3. ed. Campinas: Ed. Unicamp, 1995. Discurso e Texto: formação e circulação dos sentidos. Campinas, SP: Pontes, 2001. 
Análise de discurso: princípios \& procedimentos. Campinas: Pontes, 1999.

RIBEIRO, Darcy. Os índios e a civilização: a integração das populações indígenas no Brasil moderno. São Paulo: Companhia das Letras, 1986.

SEYFERTH, Giralda. A Idéia de Cultura Teuto-Brasileira: Literatura, Identidade e os Significados da Etnicidade. Horizontes Antropológicos, Porto Alegre, ano 10, n. 22, p. 149-197, jul./dez. 2004.

SILVA, Tomaz Tadeu. (Org). Identidade e diferença - a perspectiva dos estudos culturais. Petrópolis: Vozes, 2000, 133p.

RODRIGUES, Cintia Régia. A construção da política indigenista na república brasileira a partir das ideias de modernidade. Tellus (UCDB), v. 21, p. 203, 2012.

Os indígenas e o SPILTN na imprensa catarinense do século XIX. Anais do XI Congresso Internacional de Estudos Ibero-Americanos (CIEIA) 17 a 19 de outubro de 2017. Disponível em: http://ebooks.pucrs.br/edipucrs/ acessolivre/anais/cieia/assets/edicoes/2017/arquivos/10.pdf. Acesso em: 21/03/2019. 